OPEN ACCESS

Edited by:

Julie Messier,

University of Waterloo, Canada

Reviewed by:

C.-Elisa Schaum,

Universität Hamburg, Germany

Xiankai Lu,

South China Botanical Garden (CAS),

China

*Correspondence:

Dorothee Hodapp

dorothee.hodapp@hifmb.de

Specialty section

This article was submitted to

Biogeography and Macroecology,

a section of the journal

Frontiers in Ecology and Evolution

Received: 31 August 2018

Accepted: 11 December 2018

Published: 14 January 2019

Citation:

Hodapp D, Hillebrand $H$ and Striebel M (2019) "Unifying" the Concept of Resource Use Efficiency in

Ecology. Front. Ecol. Evol. 6:233.

doi: 10.3389/fevo.2018.00233

\section{"Unifying" the Concept of Resource Use Efficiency in Ecology}

\author{
Dorothee Hodapp $^{1 *}$, Helmut Hillebrand ${ }^{1,2}$ and Maren Striebel ${ }^{2}$ \\ ${ }^{1}$ Helmholtz Institute for Functional Marine Biodiversity (HIFMB), University of Oldenburg, Oldenburg, Germany, ${ }^{2}$ Institute for \\ Chemistry and Biology of the Marine Environment (ICBM), University of Oldenburg, Oldenburg, Germany
}

Resource use efficiency (RUE) is an ecological concept that measures the proportion of supplied resources, which is converted into new biomass, i.e., it relates realized to potential productivity. It is also commonly perceived as one of the main mechanisms linking biodiversity to ecosystem functioning based on the assumption that higher species numbers lead to more complementary and consequently more efficient use of the available resources. While there exists a large body of literature lending theoretical and experimental support to this hypothesis, there are a number of inconsistencies regarding its application: First, empirical tests use highly divergent approaches to calculate RUE. Second, the quantification of RUE is commonly based on measures of standing stock instead of productivity rates and total pools of nutrients instead of their bioavailable fractions, which both vary across systems and therefore can introduce considerable bias. Third, conceptual studies suggest that the relationship between biodiversity, productivity and RUE involves many more mechanisms than complementary resource use, resulting in variable magnitude and direction of biodiversity effects on productivity. Moreover, RUE has mainly been applied to single elements, ignoring stoichiometric, or metabolic constraints that lead to co-limitation by multiple resources. In this review we illustrate and discuss the use of RUE within and across systems and highlight how the various drivers of RUE affect the diversity-productivity relationship with increasing temporal and spatial scales as well as under anthropogenic global change. We illustrate how resource supply, resource uptake and RUE interactively determine ecosystem productivity. In addition, we illustrate how in the context of biodiversity and ecosystem functioning, the addition of a species will only result in more efficient resource use, and consequently, higher community productivity if the species' traits related to resource uptake and RUE are positively correlated.

\footnotetext{
Keywords: resource limitation, uptake, productivity, biodiversity, ecological stoichiometry, diminishing marginal returns, ecosystem functioning
}

\section{RUE IN ECOLOGY}

Resource use efficiency (RUE) is defined as the amount of biomass produced per unit of supplied resource. It is commonly applied to explain and understand ecological phenomena such as the link between potential and realized productivity or biodiversity effects on ecosystem biomass production, and therefore constitutes a concept of major interest to research questions in various ecological contexts. 
The origins of the concept go back to early agricultural research. In a comprising review, de Wit (1992) summarizes how during the agricultural industrialization, the increasing use of fertilizers and the ensuing environmental consequences triggered ideas to define the optimal supply of resources so as to maximize the efficiency of agricultural production. This agricultural view on resource use efficiency dates back to the law of the minimum (Sprengel, 1826; Liebig, 1840) and Liebscher's (1895) law of the optimum, which defines the optimal supply rate and ratio of mineral nutrients to foster plant growth. Based on Liebscher's work, Mitscherlich (first in 1909) and others expressed the decelerating production of biomass with linear increases in fertilizer addition as a law of diminishing returns. Derived from this work in agricultural sciences, ecology developed similar questions, but focused on morphological or physiological mechanisms regulating the observed patterns in resource use and its efficiency (Vitousek, 1982; Chapin et al., 1997).

Its oldest and most direct conceptual application is clearly the link between potential and realized productivity within and across communities and ecosystems (for a full history of this debate, see the supplement published with Grace et al., 2016). The higher the proportion of resources turned into new biomass, the higher are the levels of realized productivity. In that respect, RUE can be understood analogously to Odum's concept of transfer efficiency (Odum, 1957) which describes the amount of energy that is transferred from one trophic level to the next measured in, e.g., joules. Similar to reductions in energy transfer due to respiration at each trophic level, the amount of resource or matter that is converted to biomass at the next higher trophic level is constrained. Reasons are manifold and include inaccessibility of resources (Soares et al., 2017), stoichiometric mismatch and the need to respire, excrete, or exudate excess resources (Andersen et al., 2004) as well as co-limitation (Danger et al., 2008). Consequently, transfer efficiency and RUE determine important emergent properties of ecosystems such as food chain length (Hessen et al., 2004) or the internal (re)cycling of nutrients (Vitousek, 1982). Also, community composition and biodiversity turnover are affected by RUE, as species differ in their ability to sequester resources and turn these into growth. Tilman's competition theory (1982) is directly based on these ideas, predicting that the outcome of resource competition will be directly linked to community-wide RUE.

The growing interest in understanding RUE as a fundamental constraint of realized productivity over the last decades has been driven by research on how species diversity affects community or ecosystem production. The central hypothesis of the biodiversity-ecosystem functioning (BEF) research is that higher levels of diversity (species richness, functional diversity) result in a more efficient use of the available resources and will therefore yield greater amounts of biomass than the same system at lower levels of diversity (Chapin et al., 1997; Loreau, 2001). In other words, species loss will result in a reduction of RUE and therefore decreased ecosystem function (Cardinale et al., 2006). In addition to ample support for this general hypothesis from theoretical work and experimental studies, there also exists an increasing number of empirical tests, especially from natural communities (Filstrup et al., 2014; Hodapp et al., 2015; Fontana et al., 2018), highlighting the importance of individual traits rather than simple diversity measures. Acknowledging this trait-dependence results in potentially different signs and strengths of BEF relationships, as different relationships between traits mediating coexistence and traits mediating RUE can exist (Hillebrand and Matthiessen, 2009). This implies potentially high degrees of context dependence in BEF relationships, which requires to shed light on RUE as a central mechanism linking composition and function in ecological systems (Nijs and Impens, 2000; Binkley et al., 2004; Forrester and Bauhus, 2016).

However, as we detail below, the way RUE has been used in ecology generally, and BEF research especially, differs broadly. This includes conceptual and mathematical differences, which come with rarely-stated specific assumptions in the way RUE is implemented. Therefore, in this review paper, we aim to unify the concept of RUE across different types of ecological systems and scales of ecological organization, as well as spatial and temporal extent to identify and describe common mechanisms and distinguish these from system- or organismspecific phenomena. Based on an overview of the existing use of the concept (section Definitions and Differences in RUE Across Systems: Interpretation and Limitations), we present the basis for a unified view on RUE (section Unifying the Concept of RUE: a Suggestion). We discuss the validity of this concept in light of recent discussions on multiple resource limitation (section RUE Under Multiple Resource Limitation) and across scales (section RUE Across Ecological, Temporal, and Spatial Scales). Finally, we specifically address the importance of RUE in the context of global change (section RUE in a Changing Environment) and BEF (Section Biodiversity Effects on RUE) research.

\section{DEFINITIONS AND DIFFERENCES IN RUE ACROSS SYSTEMS: INTERPRETATION AND LIMITATIONS}

Despite the common applicability of RUE as a concept, measurement and quantification of the relevant quantities vary considerably across ecosystems. These differences arise from distinct types of resource use, organism physiology, and ecosystem properties. Table 1 gives an overview of examples for the definition and quantification of resource use efficiency for different types of resources, ecosystems, and organisms.

One early suggestion of how to quantify nutrient use efficiency in plants goes back to (Chapin, 1980). He stated that the resource use efficiency defined as the amount of dry matter produced per unit nutrient taken up (e.g., g biomass/g nutrient) is simply the inverse of nutrient concentration in plant tissue (e.g., expressed as $\%$ nutrient in dry mass or g nutrient/g tissue). In addition, he mentioned that future productivity could be influenced by mechanisms such as luxury consumption or accumulation of storage polysaccharides and that consequently respiration or 
TABLE 1 | Examples for definitions and uses of resource use efficiency for different organism types along different ecological scales.

\begin{tabular}{|c|c|c|c|c|c|c|}
\hline $\begin{array}{l}\text { Limiting } \\
\text { resource }\end{array}$ & Organism type & Definition & Measured as & Ecological scale & References & Limitation \\
\hline Nutrient & Terrestrial plants & $\begin{array}{l}\text { Inverse of nutrient } \\
\text { concentration in plant tissue }\end{array}$ & Tissue nutrient concentration & $\begin{array}{l}\text { Individual } \\
\text { organism/ } \\
\text { community }\end{array}$ & Chapin, 1980 & $\begin{array}{l}\text { Only valid for } \\
\text { short-lived plants }\end{array}$ \\
\hline Nutrient & Forest & $\begin{array}{l}\text { Inverse of nutrient } \\
\text { concentration in the } \\
\text { aboveground litterfall, root } \\
\text { turnover and organic matter } \\
\text { increment of vegetation }\end{array}$ & $\begin{array}{l}\text { Litterfall mass/ litterfall N } \\
\text { content }\end{array}$ & $\begin{array}{l}\text { Individual } \\
\text { organism/ } \\
\text { community }\end{array}$ & Vitousek, 1982 & $\begin{array}{l}\text { Assumption that } \\
\text { litterfall is a } \\
\text { constant } \\
\text { proportion of } \\
\text { ANPP }\end{array}$ \\
\hline Nutrient & Microbial & $\begin{array}{l}\text { Fraction of consumed } \\
\text { organic } N \text { that is not } \\
\text { released as ammonium }\end{array}$ & $\begin{array}{l}\left(U_{N}-M_{N}\right) / U_{N} \\
U N \text {, gross rates of amino-acid } \\
\text { consumption } \\
\text { MN, gross } N \text { mineralization } \\
\text { rate determined via stable } \\
\text { isotope analysis }\end{array}$ & Community & $\begin{array}{l}\text { Mooshammer et al., } \\
2014\end{array}$ & \\
\hline Nutrient & $\begin{array}{l}\text { Terrestrial } \\
\text { ecosystems }\end{array}$ & Nutrient uptake & Left over nutrient in soil & Ecosystem & Cardinale et al., 2006 & \\
\hline Nutrient & Marine Plankton & $\begin{array}{l}\text { Amount of } \mathrm{C} \text { or nutrient } \\
\text { incorporated into biomass }\end{array}$ & $\begin{array}{l}\text { Copepod RUE was calculated } \\
\text { total copepod C produced } \\
\text { per unit algal N } \\
\text { Copepod NUE was calculated } \\
\text { as copepod tissue } N \text { per unit } \\
\text { algal N }\end{array}$ & Community & Plum et al., 2015 & Standing stock \\
\hline Water & $\begin{array}{l}\text { Terrestrial, forest, } \\
\text { peatlans, } \\
\text { grassland }\end{array}$ & $\begin{array}{l}\text { The amount of } \mathrm{C} \\
\text { assimilated per unit of water } \\
\text { loss by transpiration or } \\
\text { inverse of transpiration ratio }\end{array}$ & GPP/ transpiration & Ecosystem & $\begin{array}{l}\text { Briggs and Shantz, 1913; } \\
\text { Cowan and Farquhar, } \\
\text { 1977, see also Brümmer } \\
\text { et al., } 2012\end{array}$ & \\
\hline Radiation & Forest ecosystems & $\begin{array}{l}\text { GPP per unit radiation } \\
\text { intercepted by terrestrial } \\
\text { vegetation }\end{array}$ & $\begin{array}{l}\text { Net ecosystem exchange } \\
\text { fluxes of } \mathrm{CO}_{2} \text { /absorbed } \\
\text { photosynthetically active } \\
\text { radiation (PAR) }\end{array}$ & Ecosystem & Garbulsky et al., 2010 & \\
\hline Carbon & Microbial & $\begin{array}{l}\text { Biomass } \mathrm{C} \text { produced per } \\
\text { unit organic carbon } \\
\text { resource } \mathrm{C} \text { consumed }\end{array}$ & $\begin{array}{l}\text { Growth rate/(growth rate + } \\
\text { respiration rate) }\end{array}$ & Community & Keiblinger et al., 2010 & \\
\hline
\end{tabular}

The limiting resources used for the examples as well as possible limitations of the respective measurements are given.

rates of photosynthesis and assimilation might be more adequate measures of the efficiency of nutrient use. Vitousek (1982) further pointed out that the definition of inverse concentrations in plant tissue can only be applied to short-lived plants, because in perennial plant species seasonal processes, such as withdrawal of nutrients from senescing leaves, allow within-individual recycling of nutrients. He suggested quantifying resource use efficiency as the inverse of the nutrient concentration of the aboveground litterfall, root turnover, and the organic matter increment. However, this approach only works when litterfall mass is a constant proportion of ecosystem production, which is usually not the case since higher proportions of nutrients are allocated to wood production than leaf production across gradients of forest productivity (Binkley et al., 2004).

Water use efficiency (WUE) in plant communities is usually quantified as ratios of gross primary production 
over transpiration, i.e., unit of water loss (Garbulsky et al., 2010; Niu et al., 2011; Brümmer et al., 2012). In aquatic systems, RUE usually refers to biomass production per unit of nitrogen or phosphorus. Here, biomass production is commonly quantified as some measure of standing stock (particulate carbon, biovolume, or other proxies, such as chlorophyll a concentration for phytoplankton) and divided by values of total pools of the limiting nutrient (Ptacnik et al., 2008) or similar quantities representing the degree of nutrient limitation (Breton et al., 2017). Another example is the approach by Hood et al. (2018) who used the ratio of net primary production, calculated as the difference between gross primary production (GPP) and autotrophic respiration divided by nutrient uptake as a measure for RUE of the autotroph community. Rates of GPP are generally laborious or even infeasible to obtain, especially in the field. Hence, the above definitions all use measures of standing stock as proxies for productivity. However, few studies report actual rates, such as photosynthetic capacity per leaf nitrogen content (Field and Mooney, 1983) and ratios of productivity rates over nutrient supply (Lehtinen et al., 2017).

Thus, the major divide between different applications of RUE is the difference between using gross and net production, and replacing the latter with estimates of standing stock. This is crucial as it has strong implications for interpretation. Gross production is an estimate of realized productivity including losses (exudation, excretion, or mortality through senescence and consumption), whereas especially in aquatic systems, realized productivity is often only weakly related to standing stock at all. Hence, a major drawback of using estimates of standing stock instead of productivity rates is that it is impossible to determine biomass losses due to consumption, which is a bias that will differ strongly between ecosystems.

For example, one general difference between aquatic and terrestrial systems is that aquatic systems are characterized by rapidly growing primary producers, which are more efficiently consumed by herbivores (Shurin et al., 2006). In part, this originates from better palatability of phytoplankton compared to terrestrial plants due to lower proportions of low-quality structural components, such as lignin or cellulose (Hessen et al., 2004). Consequently, aquatic systems have higher energy transfer efficiency compared to terrestrial ecosystems (Cebrian, 1999).

However, other system-specific caveats in using gross or net productivity or standing stocks also apply. In forests, nitrogen use efficiency (NUE) depends on resource resorption from senescing leaves and should therefore be integrated over the whole year, which is hardly feasible in most studies (Birk and Vitousek, 1986). Thus, any resource use efficiency determined based on standing stock values is confounded by system-specific conditions, which complicates the interpretation of observed differences between systems.

Similar issues are debated regarding differing ways to quantify the amount of limiting resource in a system. Using total resource pools such as soil $\mathrm{N}$ or $\mathrm{P}$, or total $\mathrm{N}$ and $\mathrm{P}$ in water, ignores the fact that not all of this pool may be available to organisms. Additionally, bioavailability of resources differs considerably between nutrient types (Soares et al., 2017). Thus, any RUE calculated based on "total nutrient pool" measurements will inevitably deviate from the real ratio. Similar issues arise when using remaining resource concentrations in the ecosystem as a proxy since these do not reflect the available, but only the left-over resource pool.

A third line of differences between RUE approaches captures the identity of the potentially limiting resources (Table 1), which reflects different physiological processes and their distinct resource requirements, as well as system-specific constraints on availability. For example, contrary to aquatic systems, water availability is one of the most crucial and limiting factors to plant growth and photosynthesis in terrestrial systems (Farooq et al., 2012). Therefore, water use efficiency (WUE) is only relevant in a terrestrial setting. Several approaches to RUE in autotroph organisms focus on photosynthesis, i.e., relate to the efficiency of using light energy and water to transform atmospheric $\mathrm{CO}_{2}$ into biomass. Thereby, water use efficiency (WUE) and light use efficiency (LUE) in plants mainly reflect processes of carbon fixation and thus differ from nitrogen use efficiency, which is the result of carbon fixation AND protein synthesis. Heterotrophic organisms, in contrast to autotrophs, rely on organic carbon as their main energy source and their growth is majorly constrained by the nutrient content of their diet (Hessen et al., 2004). Therefore, the energy and the matter related aspects of RUE are rather tightly coupled. In heterotrophic microbes, however, the balance between metabolic processes is highly regulated and therefore resource use of carbon as well as nitrogen and other nutrients is rather flexible (Keiblinger et al., 2010; Mooshammer et al., 2014). Thus, although RUE definitions for different types of resource or organism might resemble each other, the observed patterns will likely vary as RUE is regulated by different mechanisms.

\section{UNIFYING THE CONCEPT OF RUE: A SUGGESTION}

Given the plethora of alternative definitions and proxies for variables in numerator and denominator of the ratio quantifying RUE, it might be worthwhile taking a step back to reconsider what exactly RUE is supposed to represent and under what circumstances the common assumptions hold. According to its general definition, RUE is the ratio of the amount of biomass produced (i.e., productivity) per unit resource. However, regardless of the difficulties in choosing the most adequate or representative variables for its quantification, the relationship between resource availability and productivity is far from trivial as it involves essentially two processes, the uptake and the conversion of resources into biomass. This aspect is illustrated by the "production ecology equation" (Monteith and Moss, 1977; Binkley et al., 2004, Eqn. 1), where the realized gross productivity of a system is determined by the amount of resource supplied, the proportion of resource taken up, and the efficiency of converting the ingested resource into new biomass.

$$
\begin{aligned}
\mathrm{GPP}= & \text { resource supply } \mathrm{x} \text { resource uptake } \mathrm{x} \text { resource use } \\
& \text { efficiency }
\end{aligned}
$$


Depending on the relative increase or decrease of each of the three components in the equation and the position along the resource supply axis, productivity can show correlations of either direction with RUE. Hence, interpretation of empirical patterns becomes less straightforward. However, the knowledge of potential feed-back mechanisms and interactions between these three components offers the opportunity to understand diverging patterns across environmental conditions and systems.

For example, the common assumption originating from the concept of "diminishing marginal returns" (de Wit, 1992) describes a decelerating increase of biomass accumulation with an increasing supply of resource (Figure 1). This implies decreasing levels of RUE with increasing resource supply (Niu et al., 2011), but this assumption does not hold in general (Binkley et al., 2004). An addition of resources can lead to both, enhanced or reduced, RUE in the resource that was manipulated (Han et al., 2016, see also sections RUE Under Multiple Resource Limitation and RUE Across Ecological, Temporal, and Spatial Scales). Binkley et al. (2004) show that higher water supply increased the amount of light captured by a clonal eucalyptus stand, but these increased levels of light capture were lower than the increase of GPP, which indicates an increase in RUE of light. Similarly, water uptake increased in response to elevated water availability, but again the differences were smaller than the relative changes in GPP, indicating higher levels of WUE (Binkley et al., 2004).

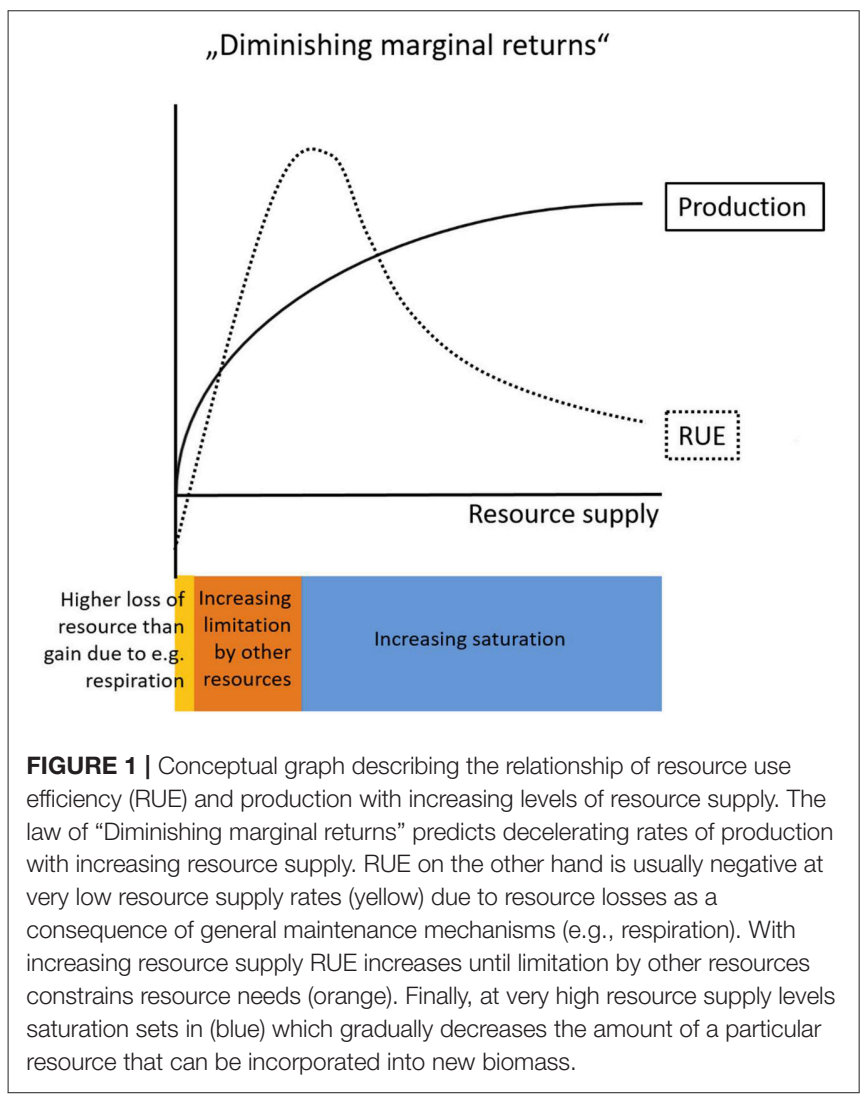

In fact, the effect of increased resource supply on productivity depends on the scale of operation (leaf vs. canopy) and the type of resource (light vs. nutrients) (see section RUE Across Ecological, Temporal, and Spatial Scales). In terrestrial ecosystems, the assumption of decreasing RUE as resource supply increases at least partly holds at the leaf level. Physiological constraints lead to negative net gains of resource (i.e., higher losses due to for example respiration than gains in resource) and accordingly negative RUE values at very low levels of resource supply. As a consequence, RUE must increase at the lower end of resource supply until it is increasingly constrained by limitation from other resources and finally decreases as the saturation point for a particular resource is reached (Figure 1). However, the RUE patterns at the leaf scale can vary substantially from patterns at higher organismal or ecological level (see section RUE Across Ecological, Temporal, and Spatial Scales). The difference between these observed patterns arise from the variable forms of relations between resource uptake and somatic (or numerical) growth. Growth directly depends on external resource supply only if there is no storage involved, otherwise growth depends on the internally available resource stocks (e.g., cell quotas, i.e., intracellular level of the limiting nutrient) (Monod, 1950; Droop, 1983). In phytoplankton, the ratio between minimal cell quota (reflecting demand) and maximal cell quota (reflecting storage) can give information on the degree of luxury consumption possible, i.e., to what extent an organism is able to take up and store surplus resources. The potential decoupling of supply and production through luxury uptake and storage differs between resource types and organisms leading to different relationships between resourcesupply and RUE at the individual scale and above. Moreover, it allows for preemption effects, where RUE is not driven by the potentially most productive species but by species able to monopolize resources through rapid uptake (Schmidtke et al., 2010; Kardol et al., 2013).

Most established ways of calculating RUE do not consider uptake explicitly, as in many empirical situations disentangling uptake and conversion efficiency is not trivial. Still, we recommend the use of the ecology production equation in order to explicitly state the assumptions underlying the calculations (Figure 2). This also implies to acknowledge different roles for both functional response (i.e., intake rate of a consumer as a function of resource density) and numerical responses (i.e., consumer population density as a function of resource density) to resource gradients, which has strong implications for altering the supply to RUE relationship at different levels of organization (see section RUE Across Ecological, Temporal and Spatial Scales).

\section{RUE UNDER MULTIPLE RESOURCE LIMITATION}

For decades, primary production in communities was considered to be limited by the least available nutrient, reflecting the classical law of the minimum postulated by Sprengel (1826) and popularized by Liebig (1840). However, more recent evidence suggests that primary production in multispecies communities is 


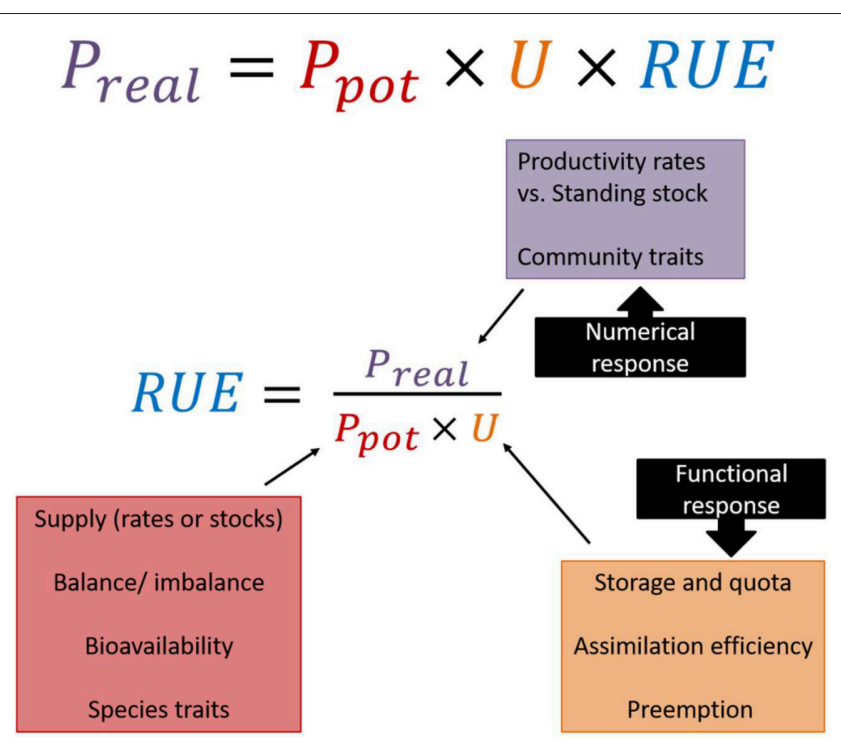

FIGURE 2 | Based on the production ecology equation, realized productivity $\left(P_{\text {real }}\right)$ is a product of potential productivity $\left(P_{\text {tot }}\right)$, resource uptake $(U)$, and resource use efficiency (RUE). Rearranging the equation gives the common definition for RUE as the realized productivity divided by the amount of assimilated resources, which is influenced by resource availability and uptake. Thus, several ecological mechanisms have to be taken into account when quantifying and interpreting RUE patterns.

frequently limited by multiple nutrients (Arrigo, 2005; Elser et al., 2007; Harpole et al., 2011). At the organism level, biochemical processes can be actively and passively co-limited by nutrients substituting each other, regulating each other's uptake rate or being equally essential (Saito et al., 2008; Bonachela et al., 2015; Sperfeld et al., 2016). At the community level, co-limitation additionally occurs as the result of individual populations being limited by different resources (Danger et al., 2008).

The predominance of co-limitation has also direct consequences for the definition of RUE, which in most cases is defined as biomass production (realized productivity) per single, limiting resource reflecting potential productivity. Until now, co-limitation of resources has been little considered when using RUE (but see Lehtinen et al., 2017, who include resource availability and resource ratios in their (phytoplankton) model; Hirose and Bazzaz, 1998; Tarvainen et al., 2015; Han et al., 2016). Here, we discuss the importance of acknowledging resource ratios when addressing RUE (section Stoichiometry and RUE) and use this discussion to address RUE across multiple trophic levels (section Multiple Trophic Levels).

\section{Stoichiometry and RUE}

Multiple resource limitation can be considered in different ways when assessing RUE. One way is to explicitly mark the transition between limitation by one resource to limitation by another, e.g., by using the concept of threshold elemental ratio (TER) (Figure 3). Here, one resource is limiting at any time but the identity of the limiting resource can switch depending on the supply ratio. TER was introduced in the

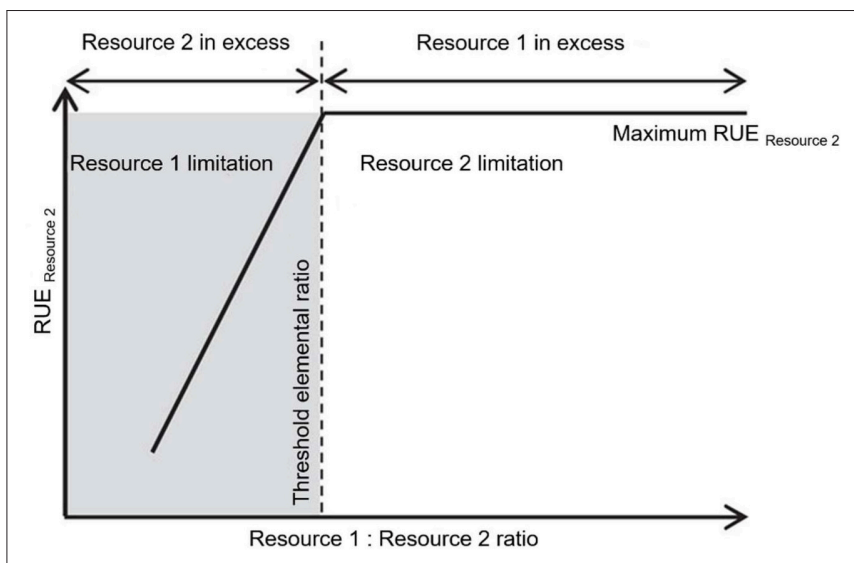

FIGURE 3 | Conceptual figure modified after (Mooshammer et al., 2014). The relation between threshold elemental ratio (TER) and resource use efficiency (RUE) depending on the available resource ratio. The TER is defined as the optimal resource elemental ratio for consumer growth (Urabe and Watanabe, 1992). The TER marks the ratio of two resources above which a maximal RUE for one resource is reached (here resource 2) as this resource becomes limiting. While the limiting resource is expected to be used for growth, the resource in excess must be disposed of.

framework of Ecological Stoichiometry (ES) (Sterner and Elser, 2002). ES is used to describe and understand the relation between organisms and populations and their surrounding environment based on the availability of and demand for multiple resources. The TER concept has been developed to understand the interactions between trophic levels (Urabe and Watanabe, 1992; Sterner, 1997; Sterner et al., 1997), especially to distinguish between energy-limited and nutrient-limited growth. Further, this approach was used to investigate consumerresource interactions (Andersen et al., 2004) and fluxes of energy and materials (Allen and Gillooly, 2009). When consumers ingest food of different chemical composition, they can be limited by energy if the C:nutrient ratio in their food is very low. With increasing C:nutrient ratio, however, the nutrient becomes so dilute in the ingested particles that growth rate decreases even if ingestion rates are maximal (Urabe and Sterner, 1996).

The threshold elemental ratio is the food C:nutrient ratio at which this switch between $\mathrm{C}$ - and nutrient limitation occurs, and can differ between consumer species by an order of magnitude, depending on nutrient requirements (Frost et al., 2006). TER thus reflects that organisms require elements for metabolism in ratios which are often different from what is available in their environment. While primary producers mainly obtain the same nutrient ratios as their environment (Elser and Urabe, 1999; Güsewell, 2004), higher trophic levels, such as zooplankton consumers or invertebrate and vertebrate taxa, keep a relatively fixed elemental body ratio, independent from the available food sources (Andersen and Hessen, 1991; DeMott et al., 1998; Elser et al., 2000; Jaenike and Markow, 2003). Therefore, consumers demand for essential nutrients and the relatively plastic balance of these nutrients in their prey can create elemental mismatches. 
Keeping such a fixed elemental body ratio and thus facing a mismatch compared to the ratios mostly manifested by producers, requires physiological mechanisms (by regulating their cellular nutrient content via excretion or respiration) and implies some costs (Elser et al., 2001; Kooijman et al., 2004; Vrede et al., 2004). Some consumers adjust their food intake by increasing the individual grazing rate with increasing mismatch between their own requirements and their food as demonstrated in a meta-analysis, pointing toward compensatory feeding responses (Hillebrand et al., 2009). Others select their food dependent on its nutritional content (Mayntz et al., 2005) or digest and retain elements in ratios different from that in the food in order to minimize the imbalances between the available food and their requirements. Below, we show that stoichiometry and stoichiometric mismatches are affected by changing environmental conditions (section RUE in a Changing Environment) and subject to adaptation on micro- and macroevolutionary time scales (section Resource Use Efficiency Across Temporal and Spatial Scales).

While TER has mainly been used to characterize the resource need of heterotrophic consumers, the concept also applies to autotrophs or mixotrophs, where the limitation between two elements switches at optimal ratios between these resources (Figure 3). This has been described as a mechanism to enhance nutrient supply under nutrient-limited conditions for phytoplankton (Rothhaupt, 1996; Klausmeier et al., 2004a,b; Hillebrand et al., 2013) as well as terrestrial plants (Wakefield et al., 2005; Farnsworth and Ellison, 2008). Recent evidence suggests that mixotrophs (i.e., organisms that are able to use different sources of energy and carbon) may buffer stoichiometric constraints for herbivores and thus stabilize secondary production compared to systems dominated by phototrophs (Moorthi et al., 2017).

A second approach to consider multiple resource limitation when assessing RUE (Figure 4) is to distinguish between balanced and imbalanced resource supply (Cardinale et al., 2009). Nutrient uptake, and therefore RUE, also depend on the balance or imbalance of resource ratios, the heterogeneity of their spatial distribution and the identity of the most limiting resource. Cardinale et al. (2009) separated between the amount of resources and the ratios of these resources by standardizing (rescaling) all resource concentrations and then using Euclidian geometry for distinguishing between resource balance and imbalance. Balanced resource supply means that all resources are equally abundant with all of them equally rare or abundant. Imbalanced resource supply indicates that some resources are available in excess while others are limiting. Studies using this approach showed that more balanced supply of resources leads to more efficient resource use and thus higher overall RUE as less resources remain unconsumed (Gross and Cardinale, 2007; Cardinale et al., 2009; Hodapp et al., 2016). This could reflect the low RUE for the overly abundant resources or the inability to access resources if uptake of multiple resources is co-dependent.

Recently, Han et al. (2016) extended a model based on the production ecology equation considering one resource (Binkley et al., 2004) to integrate multiple resource use efficiency. A

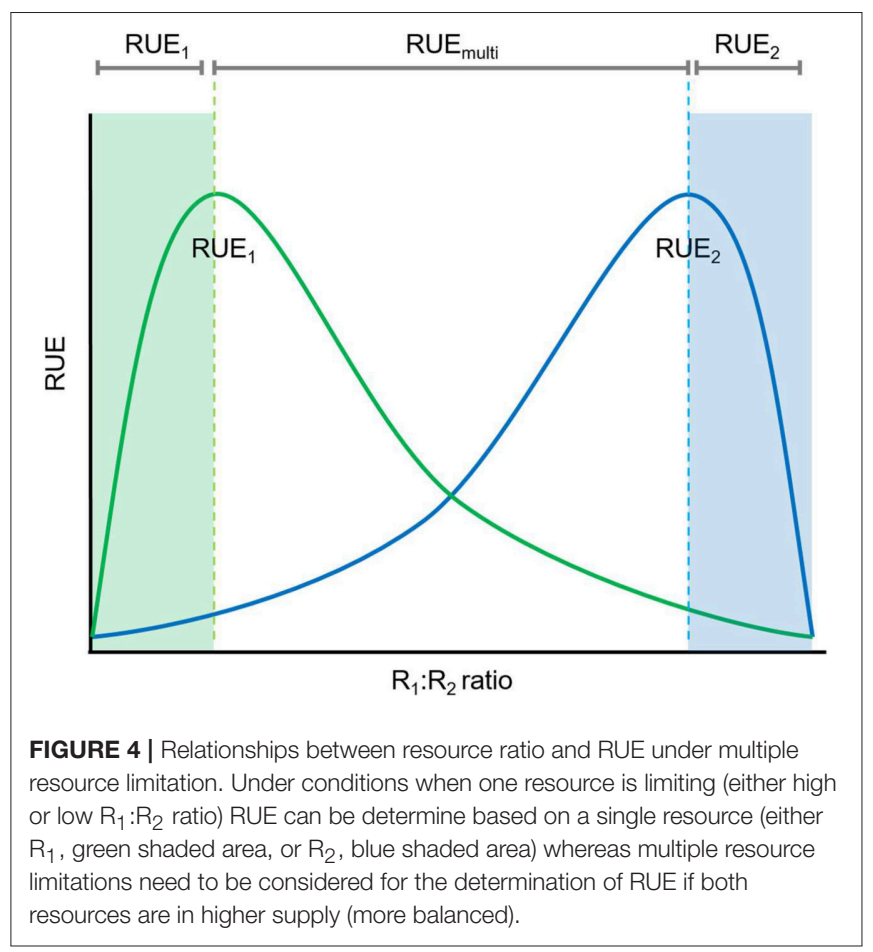

test of their algorithm on a water-availability gradient in semiarid grasslands showed that water availability affected the resource absorption rates, resource use efficiencies and resource availabilities of all three resources in their model, water, light and nitrogen, and that their interaction jointly regulated ecosystem productivity.

\section{Multiple Trophic Levels}

Approaches considering multiple resources have major appeal when addressing RUE across more than one trophic transfer. The community structure of a food web depends on the efficiency of energy transfer between different trophic levels (Hutchinson, 1959; Hairston et al., 1960). Hessen et al. (2004) argued that while energy is given in joules, carbon units are more suitable to describe both energy and matter flows. However, the efficiency of $\mathrm{C}$ transfer depends also on the cell quotas of $\mathrm{N}$ and $\mathrm{P}$ relative to C (Hessen et al., 2004). Moreover, the ratios in which consumers digest and retain elements depend on organism-specific resource limitations and might differ from that in the food material. Another example for multiple nutrient interactions across trophic levels are organisms with an intermediate role in the food web, that "repack" small food compounds by ingesting and assimilating them and thus serve as more complex food sources for higher trophic levels. In general, uptake and utilization efficiency of nutrients differ among organisms on different trophic levels and lead to differences in the release of resources, which is greater for the resource in excess. This leads to the suggestion to consider not only one but multiple resources when defining RUE among multiple trophic levels. 


\section{RUE ACROSS ECOLOGICAL, TEMPORAL AND SPATIAL SCALES}

The constraints on resource use efficiency are likely to be different at different scales of organization from individuals to ecosystems (section Resource Use Efficiency Across Scales of Organization) and also when including more environmental heterogeneity when increasing the temporal and spatial scale of inference (section Resource Use Efficiency Across Temporal and Spatial Scales).

\section{Resource Use Efficiency Across Scales of Organization}

The cellular and individual RUE are mainly characterized by the functional response of resource uptake to resource supply, reflecting the concentration-dependent on an increase in uptake as well as luxury consumption and storage. The RUE at the level of populations, communities or ecosystems involve resource use in the form of somatic growth or numerical responses (Figure 5). Moreover, the processes affecting resource demand and (co)limitation are highly different between these different scales (Danger et al., 2008; Saito et al., 2008). At the scales of cells, organs or organisms, limitation is mainly based on biochemical processes. Co-limitation occurs when the resource uptake and incorporation of one element depend on the availability of another. Within populations, genetic, and phenotypic variation between individuals creates differences in demand for-and thus limitation by-different resources. This variability will increase when considering different species or species interactions (competitive or mutualistic), as the community-level resource use differs from the one exhibited by single species (Figure 5). Thus, the role of stoichiometry of resource supply will also increase with levels of ecological

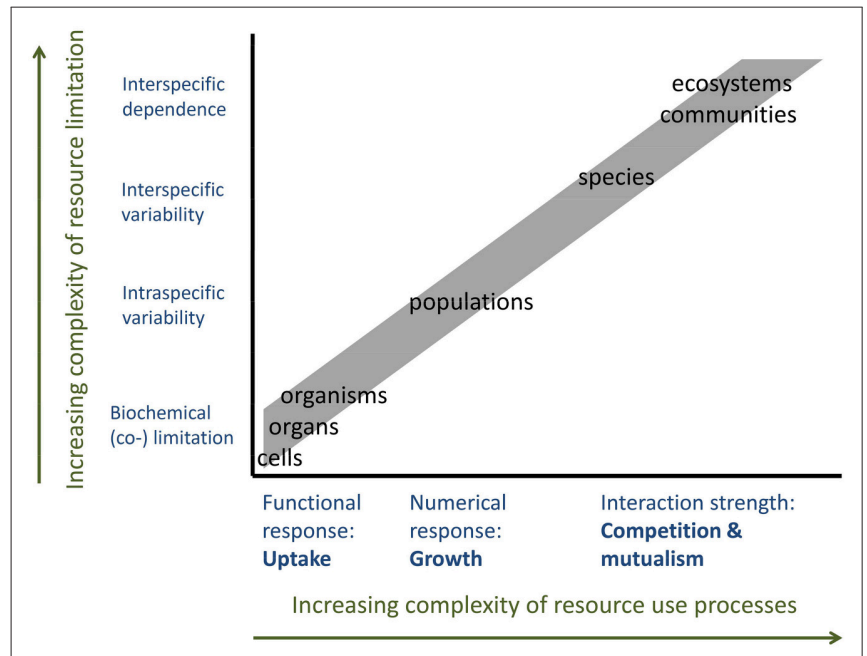

FIGURE 5 | Resource use and resource demand depending on organizational levels from single cells to ecosystems. Increasing complexity of resource use processes and types of resource limitation decrease the predictability of RUE by up or downscaling across levels of organization. complexity, especially if it includes interactions between species (Kay et al., 2005). For example, mycorrhiza-plant associations can be described as a trade-balance between the abundant access of plants to carbon and the access of the fungal partner to soil nutrients (Schwartz and Hoeksema, 1998; Johnson, 2010). Here, the shared use efficiency for the different resources is higher than predicted from each partner's specific RUE. Similar mutualistic increases in effective RUE can be found in endosymbiont bearing animals (Fenchel and Finlay, 1991), but also in ecosystem-wide facultative mutualisms (Bradley and Kenneth, 2001). In any of these cases, RUE is predicted to change when extending the scope from single individuals to species to the community level, where the directionality of change depends on the type of interaction between organisms. Mutualistic interactions and complementarity can be predicted to increase shared resource use efficiency, whereas interference competition or predation might reduce overall RUE.

Much empirical evidence supports the idea that the relationship between resource supply and RUE depends on the scale of organization. Increased precipitation decreases the efficiency of water use at the level of single leaves, but increases it at the canopy and ecosystem level (Niu et al., 2011). Likewise, leaf-scale resource use efficiency for light in trees declines with increasing irradiance, but increases at the scale of entire forests (Binkley et al., 2004). In these examples, the efficiency of the functional response decreases with supply (lower marginal gains), but the interactions between individuals and species as well as the inclusion of growth responses can lead to different relationships at the community scale. This is true beyond autotrophs. For herbivores, decreasing food quality (increasing stoichiometric mismatch between consumer and plant) leads to increased ingestion rates at the level of individuals, but decreased population or community biomass (Hillebrand et al., 2009). The latter example reflects that individuals tend to overcome shortage by compensatory functional responses, whereas poor growth efficiency leads to reduced resource use efficiency at higher levels of organization.

\section{Resource Use Efficiency Across Temporal and Spatial Scales}

Examining patterns of RUE at larger spatial and temporal scales will, in most cases, lead to an increase in the heterogeneity of resource supply rates and ratios and thereby alter RUE. The consequences of spatial heterogeneity of resource supply for RUE have been well developed in models and experiments conducted in the framework of metacommunity (Leibold and Miller, 2004) or metaecosystem (Gounand et al., 2018) ecology. In both theories, resource use in local habitats (patches) is explained from local community dynamics as well as regional processes (dispersal, mobility). Regional scale RUE will be affected by three major factors, (i) the relative difference in the resource supply between patches, (ii) the spatial connectivity between patches, and (iii) the spatial arrangement of the heterogeneity in resource supply. Theory and empirical evidence give predictions for changes in RUE across all pairwise combination of these axes (Figure 6). With respect to resource supply, models, 


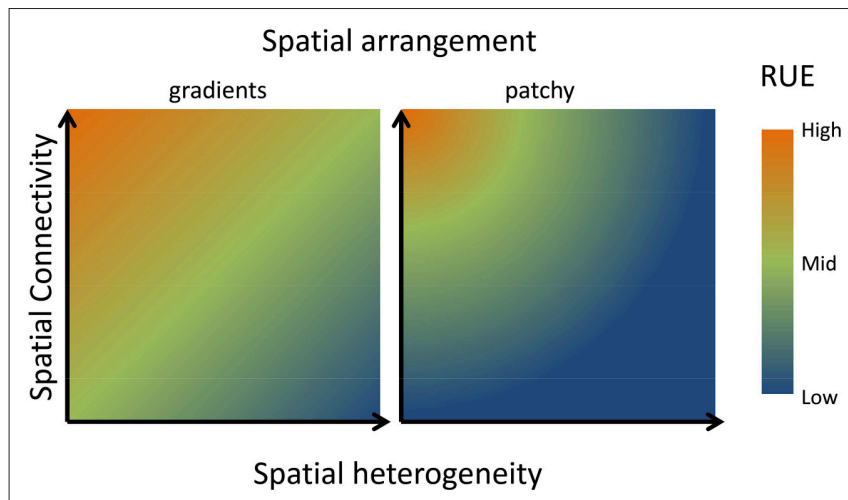

FIGURE 6 | Conceptual graph describing consequences of scaling up in space for RUE. If multiple resources are more heterogeneously distributed in space, RUE will decline unless high spatial connectivity (high rate of dispersal or active movement of consumer) allows efficient capture of multiple resources across the resource landscape (Hodapp et al., 2016). Thus, RUE will be minimal if resources are heterogeneously distributed, but low connectivity prevents consuming resources in different patches. The positive effect of dispersal or mobility decreases however, when neighboring patches differ strongly in their resource supply, reflected by the difference between a more gradual heterogeneity in the left panel compared to a more patchy difference in resource supply in the right panel. As detailed in the text, similar arguments can be made for temporal fluctuations in resource supply.

and experiments converge on the conclusion that a more heterogeneous landscape of resource supply leads to overall lower RUE at the landscape scale. On the one hand, the heterogeneity affects how well resource uptake traits match the local environment. On the other hand heterogeneity in multiple resources likely leads to stoichiometric imbalances, leading to higher amounts of resources left over and lowered multi-element RUE (Gross and Cardinale, 2007; Hodapp et al., 2016; Gülzow et al., 2019). Consequently, the RUE at larger spatial scales becomes more dependent on the variability and complementarity of resource traits between species (Cardinale et al., 2004; Hodapp et al., 2016). Regarding spatial connectivity, spatial connectivity alters the spatial imprint on RUE if diffusive processes homogenize resource differences (Gülzow et al., 2019) or organisms are able to move between patches (Marleau et al., 2015). In both cases, resource supply will be experienced as less heterogeneous and regional RUE will not decrease as much as in a low connectivity system (Figure 6). Extending these predictions, stoichiometric distribution models have been developed to address how the RUE of a spatially foraging consumer will eventually lead to spatial patterns in resource stoichiometry (Leroux et al., 2017).

Both axes will be altered by the spatial distribution of resources (Hodapp et al., 2016). In a landscape characterized by smooth resource gradients, neighboring patches are similar in their resource supply, and a short-distance disperser is likely to find similar resource conditions as in its original patch, increasing RUE (Figure 6). By contrast, in a landscape where resources are much more randomly distributed, a species performing well in one patch and producing a lot of offspring might disperse into neighboring patches with highly different resource supply, where its RUE will be low. Depending on the relative strength of dispersal compared to local responses of population growth to resource availability, a very patchy distribution of resources will be detrimental to overall resource use.

In contrast to the large number of studies examining RUE in space, there is a much smaller body of literature on the effect of larger temporal scales on RUE. However, in principle the same arguments prevail: RUE will decrease when measured over longer time scales if different resources are supplied asynchronously, leading to temporal imbalance in supply stoichiometry, analogous to the spatial supply imbalance (Figure 6). This effect will be less prominent if long-lived species can integrate over the fluctuations in supply, analogous to the effect of connectivity in space. RUE will also be higher if changes in temporal supply are gradual, whereas pulsed, abrupt changes will decrease the match between resource use traits and resource availability (Figure 6). A nice support for this analogy is a study on Norwegian spruce stands, showing that RUE peaks for different resources occurred in different seasons (Tarvainen et al., 2015).

On evolutionary time scales, the stoichiometric match between resource requirements and supply ultimately determines the trade-off between the material and energetic costs of a particular trait or strategy and its fitness benefits (Kay et al., 2005). For instance, resources that are allocated to structural components as opposed to fast growth can be valuable investments if they are beneficial in terms of reproductive success. Thus, flexibility in elemental ratios and therefore mechanisms driving RUE are subject to selective pressure.

In general, responses to spatial and temporal gradients of resource supply might differ (Paruelo et al., 1999), thus, more research joining both perspectives might be needed to assess the full scale dependency of RUE.

\section{RUE IN A CHANGING ENVIRONMENT}

Given the central role that has been ascribed to RUE in explaining biodiversity effects on ecosystem processes, it is mandatory to understand how RUE will directly be affected by anthropogenic drivers of environmental change. These drivers can be separated in two categories: those altering RUE through altering resource supply, and those altering RUE by altering the demand.

Anthropogenic changes in supply include eutrophication (or in later years also re-oligotrophication), fossil fuel burning increasing e.g., carbon dioxide availability in the atmosphere, changes in precipitation or changes in light climate, e.g., through increased turbidity. The effect of altering the availability of any of these resources will alter the RUE for this resource, where the sign depends on the non-linear relationship between supply and RUE (see section Unifying the Concept of RUE: a Suggestion, Figure 1). Additionally, changes in the supply of any resource can indirectly influence RUE for another resource, a phenomenon often observed in agricultural studies, which aim to increase productivity and RUE with minimal effort in irrigation and fertilization. Examples include increasing water use efficiency over gradients of $\mathrm{CO}_{2}$ availability (Policy et al., 1993; Keenan 
et al., 2013) and light (Aranda et al., 2007). Likewise, enhancing $\mathrm{CO}_{2}$ increased light and nutrient use efficiency (Hirose and Bazzaz, 1998).

Global warming is an example for an anthropogenic driver of global change affecting the demand rather than the supply. It has only recently been fully accepted that one of the consequences of global warming is that the inevitable increase in base metabolic rates and growth rates alters the absolute and relative demands for nutrients. One of the most elegant examples is the model by Thomas et al. (2017) that shows how the minimal requirements for a nutrient increase with temperature, whereas simultaneously an increase in nutrient supply allows for a thermal optimum shifted to higher temperatures. While others have argued that the increase in demand might be alleviated by higher efficiency in resource use (Toseland et al., 2013), there is evidence from studies on phytoplankton showing that half saturation constants for nutrients increase with temperature (Bestion et al., 2018) or that internal algal stoichiometry reflects higher relative nutrient limitation (Yvon-Durocher et al., 2015). A recent study investigating combined temperature and supply level effects on phytoplankton community growth (Verbeek et al., 2018) showed that whereas single treatments of temperature increase or oligotrophication led to increases in RUE, the combined treatment resulted in non-linear responses, reflecting the mismatch between increasing demand and decreasing supply. Similarly, shifts in biochemical composition of zooplankton species with increasing temperature were shown, where the sign of the effect was dependent on resource availability (Bullejos et al., 2014). In addition to effects of increasing mean temperature, species responses to changes in temperature variance are also governed by asymmetric thermal performance curves. In most cases, performance declines faster at superoptimal temperatures than it increases at suboptimal temperatures. Consequently, the effect of temperature fluctuations on growth rate (and thus resource demand) in the short term can be net positive or net negative depending on the degree of asymmetry in the thermal performance curve (Bernhardt et al., 2018). On longer time scales different adaptive response were shown to evolve under different timescales depending on the frequency of the environmental fluctuation (Botero et al., 2015). Thus, the changes in demand and supply of resources that interactively shape responses of RUE are influenced by the magnitude and fluctuation of environmental properties.

\section{BIODIVERSITY EFFECTS ON RUE}

A common perception among ecologists is that higher levels of diversity (richness and evenness) generally result in higher levels of depletion of the supplied resources, i.e., resource use efficiency, which then leads to an increase in biomass production (Figure 7). While there is plenty of theoretical and empirical support for this assumption for mainly terrestrial ecosystems (Cardinale et al., 2006), the general patterns show quite a variability across systems (Balvanera et al., 2006). In fact, study outcomes from natural systems suggest a considerable flexibility of diversity effects on
RUE and production (Filstrup et al., 2014; Gagic et al., 2015; Hodapp et al., 2015; Fontana et al., 2018).

As illustrated by the production ecology equation, system productivity is determined by more than just RUE. In fact, the common diversity effects, such as complementarity, selection, and facilitation are, strictly speaking, associated with resource uptake rather than resource use efficiency itself (Nijs and Impens, 2000). As illustrated earlier, resource uptake is intricately related to and regulated by RUE through resource demand, depending on environmental conditions, species interactions, and metabolic constraints.

However, whether increased species richness yields higher biomass depends on the resource use efficiency traits of the species that is added to the system. Given a system with a certain number of species and the associated RUE, increasing community richness by just a single species will result in the re-distribution of resources within the species community and any resource re-distributed from a species with high RUE to a new species with lower RUE will result in a reduction of community productivity (Nijs and Impens, 2000). An appropriate example is phytoplankton communities, where the potential for complementarity effects is lower due to the rather homogeneous aquatic environment and the fact that plankton are floating freely in the water column, i.e., they have similar access to nutrients. Schmidtke et al. (2010) showed experimentally that instead of increasing biomass, all of their tested algal communities declined in biomass when adding further functional groups to the species assemblage. They ascribe this pattern to a trade-off between growth rate and the ability to build larger amounts of biomass as slowgrowing species produced higher biovolumes in monoculture, but were outcompeted by fast-growing, less productive species in the species mixtures. Hence, positive effects of diversity on RUE and production will only occur in case of a positive correlation between resource uptake and resource use efficiency traits of the additional species. This is not contradictory to the huge body of biodiversity-ecosystem functioning (BEF) literature, which, in the vast majority, reports positive diversity effects. Classic BEF experiments tend to influence their outcomes, because in these highly controlled environments the only reason why species coexist is usually resource complementarity. In natural systems, however, coexistence is affected by many more mechanisms, e.g., dispersal rate, (selective) grazing pressure, and environmental fluctuations.

Here, adding more species might not or even negatively affect total RUE when traits mediating coexistence are not or are negatively related to traits mediating resource use (Mouquet et al., 2002).

Additional variability in natural systems originates from the distribution of resource supply. Resource supply can be more or less heterogeneous in space, time, and the range of resource options provided, e.g., variability in nutrient ratios. In this context, more heterogeneous resource supply requires high trait diversity in uptake and/or resource use in order to achieve complementarity and high proportions of realized biomass production. On the contrary, in uniform resource environments (i.e., low heterogeneity in resource supply), resources will most 


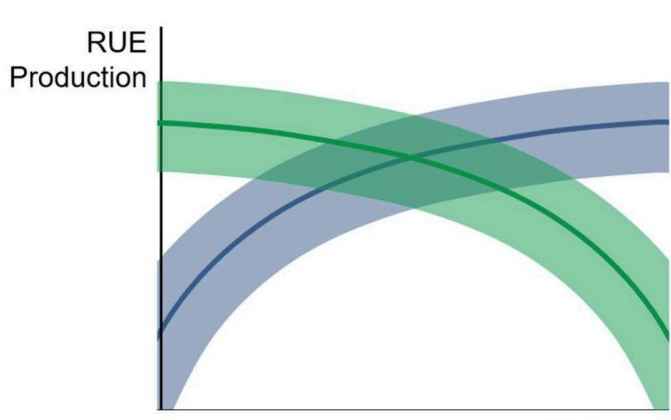

Richness

Functional diversity
Resource heterogeneity or strong correlation of traits related to uptake and RUE $\rightarrow$ addition of species increases RUE and biomass production

Resource homogeneity or weak correlation of traits related to uptake and RUE $\rightarrow$ addition of species decreases RUE and biomass production

FIGURE 7 | Conceptual figure of possible relationships between diversity measures and resource use efficiency (RUE) or productivity. Positive, neutral or negative correlations are possible, depending on the match between resource supply and species assemblage. Shaded areas indicate potential variation around the general trend.

effectively be turned into new biomass when the local community consists of one or a few species that are well adapted to the given resource conditions (Hodapp et al., 2016). However, natural environments are seldom static or uniform. Therefore, in the more common case of patchy environments and fluctuating resource conditions over time, large regional species pools, and sufficient connectivity between patches will always serve as insurance for sustaining high levels of RUE, and therefore, ecosystem functioning through time (Danger et al., 2008). These considerations also hold with regard to other environmental factors. For instance, Norberg et al. (2001) use a theoretical framework to illustrate how the phenotypic diversity effects on functioning are affected by changing environmental conditions. Empirically, this can be shown by the effect of temporal or spatial heterogeneity on BEF relationships (Allan et al., 2011; Isbell et al., 2011). More species are needed to maintain a certain fraction of the productivity in systems varying more in space or time, as the species-specific RUE decreases if there are times or places where the performance of specific species is not maximal. In other words, environmental dimensionality has to match the dimensionality of species traits in the local assemblage in order to guarantee efficient use of the given resources (Ptacnik et al., 2010), and consequently, higher productivity.

\section{CONCLUSIONS}

As discussed in the previous sections, RUE and its role in governing BEF relationships does not only vary due to organismspecific physiological properties, but also between levels of biological organization and in response to heterogeneity in environmental conditions. Thus, while the ultimate aim of studies on RUE should be to relate rates of productivity to the amount of available resource, it might not be feasible to define a general concept for the quantification and mechanisms driving RUE that is valid across types of ecosystem, organism, and resource. Albeit, any deviation from the original concept that might be necessary needs to be acknowledged and discussed when making inferential statements. New insights could be generated by testing the extension of the concept to more than one nutrient and investigating how anthropogenic alteration of environmental conditions will affect long-term changes in RUE.

\section{AUTHOR CONTRIBUTIONS}

All authors listed have made a substantial, direct and intellectual contribution to the work, and approved it for publication.

\section{ACKNOWLEDGMENTS}

The authors would like to acknowledge the organizers of the 2018 Unifying Ecology Across Scales Gordon Research Conference, Mary O'Connor and Angelica L. Gonzalez, for discussion.

$\mathrm{DH}$ acknowledges funding by the Helmholtz Association at the Institute for Functional Marine Biodiversity (HIFMB) Oldenburg, MS and $\mathrm{HH}$ acknowledge funding by the German Research Foundation (DFG: STR 1383/1-1, STR 1383/6-1, HI 848/15-1, HI 848/24-1) within the priority program DynaTrait (SPP 1704).

\section{REFERENCES}

Allan, E., Weisser, W., Weigelt, A., Roscher, C., Fischer, M., and Hillebrand, H. (2011). More diverse plant communities have higher functioning over time due to turnover in complementary dominant species. Proc. Natl. Acad. Sci. U.S.A. 108, 17034-17039. doi: 10.1073/pnas.1104015108

Allen, A. P., and Gillooly, J. F. (2009). Towards an integration of ecological stoichiometry and the metabolic theory of ecology to better understand nutrient cycling. Ecol. Lett. 12, 369-384. doi: 10.1111/j.1461-0248.2009. 01302.x

Andersen, T., Elser, J. J., and Hessen, D. O. (2004). Stoichiometry and population dynamics. Ecol. Lett.. 7, 884-900. doi: 10.1111/j.1461-0248.2004.00646.x 
Andersen, T., and Hessen, D. O. (1991). Carbon, nitrogen, and phosphoruscontent of fresh-water zooplankton. Limnol. Oceanogr. 36, 807-814. doi: 10.4319/lo.1991.36.4.0807

Aranda, I., Pardos, M., Puértolas, J., Jiménez, M. D., and Pardos, J. A. (2007). Water-use efficiency in cork oak (Quercus suber) is modified by the interaction of water and light availabilities. Tree Physiol. 27, 671-677. doi: 10.1093/treephys/27.5.671

Arrigo, K. R. (2005). Marine microorganisms and global nutrient cycles. Nature 437, 349-355. doi: 10.1038/nature04159

Balvanera, P., Pfisterer, A. B., Buchmann, N., He, J.-S., Nakashizuka, T., Raffaelli, D., et al. (2006). Quantifying the evidence for biodiversity effects on ecosystem functioning and services: biodiversity and ecosystem functioning/services. Ecol. Lett. 9, 1146-1156. doi: 10.1111/j.1461-0248.2006.00963.x

Bernhardt, J. R., Sunday, J. M., Thompson, P. L., and O'Connor, M. I. (2018). Nonlinear averaging of thermal experience predicts population growth rates in a thermally variable environment. Proc. R. Soc. B 285:20181076. doi: 10.1098/rspb.2018.1076

Bestion, E., García-Carreras, B., Schaum, C., Pawar, S., Yvon-Durocher, G., and Cameron, D. (2018). Metabolic traits predict the effects of warming on phytoplankton competition. Ecol. Lett. 21, 655-664. doi: 10.1111/ele.12932

Binkley, D., Stape, J. L., and Ryan, M. G. (2004). Thinking about efficiency of resource use in forests. For. Ecol. Manage. 193, 5-16. doi: 10.1016/j.foreco.2004.01.019

Birk, E. M., and Vitousek, P. M. (1986). Nitrogen availability and nitrogen use efficiency in loblolly pine stands. Ecology 67, 69-79. doi: 10.2307/1938504

Bonachela, J. A., Klausmeier, C. A., Edwards, K. F., Litchman, E., and Levin, S. A. (2015). The role of phytoplankton diversity in the emergent oceanic stoichiometry. J. Plankton Res. 38, 1021-1035. doi: 10.1093/plankt/ fbv087

Botero, C. A., Weissing, F. J., Wright, J., and Rubenstein, D. R. (2015). Evolutionary tipping points in the capacity to adapt to environmental change. Proc. Natl. Acad. Sci. U.S.A. 112, 184-189. doi: 10.1073/pnas.1408589111

Bradley, J. P., and Kenneth, L. H. (2001). Positive interactions between suspensionfeeding bivalves and seagrass`a facultative mutualism. Mar. Ecol. Prog. Ser. 213, 143-155. doi: 10.3354/meps 213143

Breton, E., Christaki, U., Bonato, S., Didry, M., and Artigas, L. (2017). Functional trait variation and nitrogen use efficiency in temperate coastal phytoplankton. Mar. Ecol. Prog. Ser. 563, 35-49. doi: 10.3354/meps11974

Briggs, L. J., and Shantz, H. L. (1913). The Water Requirements of Plants. 1. Investigations in the Great Plains in 1910 and 1911. USDA Bureau of Plant Industry Bulletin, 284.

Brümmer, C., Black, T. A., Jassal, R. S., Grant, N. J., Spittlehouse, D. L., Chen, B., et al. (2012). How climate and vegetation type influence evapotranspiration and water use efficiency in Canadian forest, peatland and grassland ecosystems. Agric. Forest Meteorol. 153, 14-30. doi: 10.1016/j.agrformet.2011.04.008

Bullejos, F. J., Carrillo, P., Gorokhova, E., Medina-Sánchez, J. M., and Villar-Argaiz, M. (2014). Nucleic acid content in crustacean zooplankton: bridging metabolic and stoichiometric predictions. PLOS ONE 9:e86493. doi: 10.1371/journal.pone.0086493

Cardinale, B. J., Hillebrand, H., Harpole, W. S., Gross, K., and Ptacnik, R. (2009). Separating the influence of resource 'availability' from resource 'imbalance' on productivity-diversity relationships. Ecol. Lett. 12, 475-487. doi: 10.1111/j.1461-0248.2009.01317.x

Cardinale, B. J., Ives, A. R., and Inchausti, P. (2004). Effects of species diversity on the primary productivity of ecosystems: extending our spatial and temporal scales of inference. Oikos 104, 437-450. doi: 10.1111/j.0030-1299.2004.13254.x

Cardinale, B. J., Srivastava, D. S., Emmett Duffy, J., Wright, J. P., Downing, A. L., Sankaran, M., et al. (2006). Effects of biodiversity on the functioning of trophic groups and ecosystems. Nature 443, 989-992. doi: 10.1038/nature05202

Cebrian, J. (1999). Patterns in the fate of production in plant communities. Am. Nat. 154, 449-468. doi: 10.1086/303244

Chapin, F. S. (1980). The mineral nutrition of wild plants. Ann. Rev. Ecol. Syst. 11, 233-260. doi: 10.1146/annurev.es.11.110180.001313

Chapin, F. S. I., Walker, B. H., Hobbs, R. J., Hooper, D. U., Lawton, J. H., Sala, O. E., et al. (1997). Biotic control over the functioning of ecosystems. Science 277, 500-504. doi: 10.1126/science.277.5325.500

Cowan, I. R., and Farquhar, G. D. (1977). Stomatal function in relation to leaf metabolism and environment. Symp. Soc. Exp. Biol. 31, 471-505.
Danger, M., Daufresne, T., Lucas, F., Pissard, S., and Lacroix, G. (2008). Does Liebig's law of the minimum scale up from species to communities? Oikos 117, 1741-1751. doi: 10.1111/j.1600-0706.2008.16793.x

de Wit, C. T. (1992). Resource use efficiency in agriculture. Agric. Syst. 40, 125-151. doi: 10.1016/0308-521X(92)90018-J

DeMott, W. R., Gulati, R. D., and Siewertsen, K. (1998). Effects of phosphorusdeficient diets on the carbon and phosphorus balance of Daphnia magna. Limnol. Oceanogr. 43, 1147-1161. doi: 10.4319/lo.1998.43.6.1147

Droop, M. R. (1983). 25 years of algal growth kinetics. a personal view. Botanica Marina 26, 99-152. doi: 10.1515/botm.1983.26.3.99

Elser, J. J., Bracken, M. E. S., Cleland, E. E., Gruner, D. S., Harpole, W. S., Hillebrand, H., et al. (2007). Global analysis of nitrogen and phosphorus limitation of primary producers in freshwater, marine and terrestrial ecosystems. Ecol. Lett. 10, 1135-1142. doi: 10.1111/j.1461-0248.2007. 01113.x

Elser, J. J., Fagan, W. F., Denno, R. F., Dobberfuhl, D. R., Folarin, A., Huberty, A., et al. (2000). Nutritional constraints in terrestrial and freshwater food webs. Nature 408, 578-580. doi: 10.1038/35046058

Elser, J. J., Hayakawa, K., and Urabe, J. (2001). Nutrient limitation reduces food quality for zooplankton: Daphnia response to seston phosphorus enrichment. Ecology 82, 898-903. doi: 10.2307/2680208

Elser, J. J., and Urabe, J. (1999). The stoichiometry of consumer-driven nutrient recycling: theory, observations, and consequences. Ecology 80, 735-751. doi: 10. 1890/0012-9658(1999)080[0735:TSOCDN]2.0.CO;2

Farnsworth, E. J., and Ellison, A. M. (2008). Prey availability directly affects physiology, growth, nutrient allocation and scaling relationships among leaf traits in 10 carnivorous plant species. J. Ecol. 96, 213-221. doi: 10.1111/j.1365-2745.2007.01313.x

Farooq, M., Hussain, M., Wahid, A., and Siddique, K. H. M. (2012). "Drought Stress in Plants: An Overview," in Plant Responses to Drought Stress: From Morphological to Molecular Features, ed, R. Aroca (Berlin, Heidelberg: Springer Berlin Heidelberg), 1-33.

Fenchel, T. O. M., and Finlay, B. J. (1991). Endosymbiotic methanogenic bacteria in anaerobic ciliates: significance for the growth efficiency of the host. $J$. Protozool. 38, 18-22. doi: 10.1111/j.1550-7408.1991.tb04788.x

Field, C., and Mooney, H. A. (1983). Leaf age and seasonal effects on light, water, and nitrogen use efficiency in a California shrub. Oecologia 56, 348-355. doi: $10.1007 / \mathrm{BF} 00379711$

Filstrup, C. T., Hillebrand, H., Heathcote, A. J., Harpole, W. S., and Downing, J. A. (2014). Cyanobacteria dominance influences resource use efficiency and community turnover in phytoplankton and zooplankton communities. Ecol. Lett. 17, 464-474. doi: 10.1111/ele.12246

Fontana, S., Thomas, M. K., Moldoveanu, M., Spaak, P., and Pomati, F. (2018). Individual-level trait diversity predicts phytoplankton community properties better than species richness or evenness. ISME J. 12, 356-366. doi: 10.1038/ismej.2017.160

Forrester, D. I., and Bauhus, J. (2016). A review of processes behind diversity-productivity relationships in forests. Curr. Forestry Rep. 2, 45-61. doi: 10.1007/s40725-016-0031-2

Frost, P. C., Benstead, J. P., Cross, W. F., Hillebrand, H., Larson, J. H., Xenopoulos, M. A., et al. (2006). Threshold elemental ratios of carbon and phosphorus in aquatic consumers. Ecol. Lett. 9, 774-779. doi: 10.1111/j.1461-0248.2006.00919.x

Gagic, V., Bartomeus, I., Jonsson, T., Taylor, A., Winqvist, C., Fischer, C., et al. (2015). Functional identity and diversity of animals predict ecosystem functioning better than species-based indices. Proc. R. Soc. B Biol. Sci. 282, 20142620-20142620. doi: 10.1098/rspb.2014.2620

Garbulsky, M. F., Peñuelas, J., Papale, D., Ardö, J., Goulden, M. L., Kiely, G., et al. (2010). Patterns and controls of the variability of radiation use efficiency and primary productivity across terrestrial ecosystems: global patterns in radiation use efficiency and photosynthetic uptake. Glob. Ecol. Biogeograp. 19, 253-267. doi: 10.1111/j.1466-8238.2009. 00504.x

Gounand, I., Harvey, E., Little, C. J., and Altermatt, F. (2018). Meta-ecosystems 2.0: rooting the theory into the field. Trends Ecol. Evol. 33, 36-46. doi: $10.1016 / j . t r e e .2017 .10 .006$

Grace, J. B., Anderson, T. M., Seabloom, E. W., Borer, E. T., Adler, P. B., Harpole, W. S., et al. (2016). Integrative modelling reveals mechanisms 
linking productivity and plant species richness. Nature 529, 390-393. doi: $10.1038 /$ nature 16524

Gross, K., and Cardinale, B. J. (2007). Does species richness drive community production or vice versa? Reconciling historical and contemporary paradigms in competitive communities. Am. Natural. 170, 207-220. doi: 10.1086/518950

Gülzow, N., Wahlen, Y., and Hillebrand, H. (2019). Metaecosystem dynamics of marine phytoplankton alters resource use efficiency along stoichiometric gradients. Am Natural. 193, 35-50. doi: 10.1086/700835

Güsewell, S. (2004). N : P ratios in terrestrial plants: variation and functional significance: Tansley review. New Phytol. 164, 243-266. doi: 10.1111/j.1469-8137.2004.01192.x

Hairston, N. G., Smith, F. E., and Slobodkin, L. B. (1960). Community structure, population control, and competition. Am. Nat. 94, 421-425. doi: $10.1086 / 282146$

Han, J., Chen, J., Miao, Y., and Wan, S. (2016). Multiple resource use efficiency (mRUE): a new concept for ecosystem production. Sci. Rep. 6:37453. doi: $10.1038 /$ srep 37453

Harpole, W. S., Ngai, J. T., Cleland, E. E., Seabloom, E. W., Borer, E. T., Bracken, M. E. S., et al. (2011). Nutrient co-limitation of primary producer communities. Ecol. Lett. 14, 852-862. doi: 10.1111/j.1461-0248.2011.01651.x

Hessen, D. O., Ågren, G. I., Anderson, T. R., Elser, J. J., and de Ruiter, P. C. (2004). Carbon sequestration in ecosystems: the role of stoichiometry. Ecology 85, 1179-1192. doi: 10.1890/02-0251

Hillebrand, H., Borer, E. T., Bracken, M. E. S., Cardinale, B. J., Cebrian, J., Cleland, E. E., et al. (2009). Herbivore metabolism and stoichiometry each constrain herbivory at different organizational scales across ecosystems. Ecol. Lett. 12, 516-527. doi: 10.1111/j.1461-0248.2009.01304.x

Hillebrand, H., and Matthiessen, B. (2009). Biodiversity in a complex world: consolidation and progress in functional biodiversity research: Consolidation and progress in BDEF research. Ecol. Lett. 12, 1405-1419. doi: 10.1111/j.1461-0248.2009.01388.x

Hillebrand, H., Steinert, G., Boersma, M., Malzahn, A., Léo Meunier, C., Plum, C., et al. (2013). Goldman revisited: faster growing phytoplankton has lower N:P and lower stoichiometric flexibility. Limnol. Oceanogr. 58, 2076-2088. doi: 10.4319/lo.2013.58.6.2076

Hirose, T., and Bazzaz, F. A. (1998). Trade-off between light- and nitrogenuse efficiency in canopy photosynthesis. Ann. Bot. 82, 195-202. doi: $10.1006 /$ anbo. 1998.0668

Hodapp, D., Hillebrand, H., Blasius, B., and Ryabov, A. B. (2016). Environmental and trait variability constrain community structure and the biodiversityproductivity relationship. Ecology 97, 1463-1474. doi: 10.1890/150730.1

Hodapp, D., Meier, S., Muijsers, F., Badewien, T., and Hillebrand, H. (2015). Structural equation modeling approach to the diversity-productivity relationship of Wadden Sea phytoplankton. Mar. Ecol. Prog. Ser. 523, 31-40. doi: $10.3354 /$ meps 11153

Hood, J. M., Benstead, J. P., Cross, W. F., Huryn, A. D., Johnson, P. W., Gíslason, G. M., et al. (2018). Increased resource use efficiency amplifies positive response of aquatic primary production to experimental warming. Glob. Chang. Biol. 24, 1069-1084. doi: $10.1111 / \mathrm{gcb} .13912$

Hutchinson, G. E. (1959). Homage to Santa Rosalia or why are there so many kinds of animals? Am. Nat. 93, 145-159. doi: 10.1086/282070

Isbell, F., Calcagno, V., Hector, A., Connolly, J., Harpole, W. S., Reich, P. B., et al. (2011). High plant diversity is needed to maintain ecosystem services. Nature 477, 199-202. doi: 10.1038/nature10282

Jaenike, J., and Markow, T. A. (2003). Comparative elemental stoichiometry of ecologically diverse Drosophila. Funct. Ecol. 17, 115-120. doi: 10.1046/j.1365-2435.2003.00701.x

Johnson, N. C. (2010). Resource stoichiometry elucidates the structure and function of arbuscular mycorrhizas across scales. New Phytol. 185, 631-647. doi: 10.1111/j.1469-8137.2009.03110.x

Kardol, P., Souza, L., and Classen, A. T. (2013). Resource availability mediates the importance of priority effects in plant community assembly and ecosystem function. Oikos 122, 84-94. doi: 10.1111/j.1600-0706.2012.20546.x

Kay, A. D., Ashton, I. W., Gorokhova, E., Kerkhoff, A. J., Liess, A., and Litchman, E. (2005). Toward a stoichiometric framework for evolutionary biology. Oikos 109, 6-17. doi: 10.1111/j.0030-1299.2005.14048.x
Keenan, T. F., Hollinger, D. Y., Bohrer, G., Dragoni, D., Munger, J. W., Schmid, H. P., et al. (2013). Increase in forest water-use efficiency as atmospheric carbon dioxide concentrations rise. Nature 499, 324. doi: 10.1038/nature12291

Keiblinger, K. M., Hall, E. K., Wanek, W., Szukics, U., Hämmerle, I., Ellersdorfer, G., et al. (2010). The effect of resource quantity and resource stoichiometry on microbial carbon-use-efficiency: Resource quantity/quality drives microbial C-use-efficiency. FEMS Microbiol. Ecol. 73, 430-440. doi: 10.1111/j.1574-6941.2010.00912.x

Klausmeier, C. A., Litchman, E., Daufresne, T., and Levin, S. A. (2004b). Optimal nitrogen-to-phosphorus stoichiometry of phytoplankton. Nature 429, 171-174. doi: 10.1038/nature02454

Klausmeier, C. A., Litchman, E., and Levin, S. A. (2004a). Phytoplankton growth and stoichiometry under multiple nutrient limitation. Limnol. Oceanogr. 49, 1463-1470. doi: 10.4319/lo.2004.49.4_part_2.1463

Kooijman, S. A. L. M., Andersen, T., and Kooi, B. W. (2004). Dynamic energy budget representations of stoichiometric constraints on population dynamics. Ecology 85, 1230-1243. doi: 10.1890/02-0250

Lehtinen, S., Tamminen, T., Ptacnik, R., and Andersen, T. (2017). Phytoplankton species richness, evenness, and production in relation to nutrient availability and imbalance: phytoplankton species richness, evenness, and production. Limnol. Oceanogr. 62, 1393-1408. doi: 10.1002/lno.10506

Leibold, M. A., and Miller, T. E. (2004). "From metapopulations to metacommunities," in Ecology, genetics, aned evolution of metapopulations, eds, I. Hanski and O. E. Gaggiotti (Amsterdam: Elsevier Academic Press), 133-150.

Leroux, S. J., Wal, E. V., Wiersma, Y. F., Charron, L., Ebel, J. D., Ellis, N. M., et al. (2017). Stoichiometric distribution models: ecological stoichiometry at the landscape extent. Ecol. Lett. 20, 1495-1506. doi: 10.1111/ele.12859

Liebig, J. V. (1840). Die Organische Chemie in ihrer Anwendung auf Agricultur und Physiologie. Braunschweig: Vieweg.

Liebscher, G. (1895). Untersuchung über die Bestimmung des Düngebedürfnisses der Ackeröden und Kulturpflanzen. J. für Landwirtschaft 43.

Loreau, M. (2001). Biodiversity and ecosystem functioning: current knowledge and future challenges. Science 294, 804-808. doi: 10.1126/science.1064088

Marleau, J. N., Guichard, F., and Loreau, M. (2015). Emergence of nutrient colimitation through movement in stoichiometric meta-ecosystems. Ecol. Lett. 18, 1163-1173. doi: 10.1111/ele.12495

Mayntz, D., Raubenheimer, D., Salomon, M., Toft, S., and Simpson, S. J. (2005). Nutrient-specific foraging in invertebrate predators. Science 307, 111-113. doi: $10.1126 /$ science. 1105493

Monod, J. (1950). La technique de culture continue theorie et applications. Ann. Psteur 79, 390-410.

Monteith, J. L., and Moss, C. J. (1977). Climate and the efficiency of crop production in Britain [and Discussion]. Philos. Trans. R. Soc. B Biol. Sci. 281, 277-294. doi: 10.1098/rstb.1977.0140

Moorthi, S., Ptacnik, R., Sanders, R., Fischer, R., Busch, M., and Hillebrand, H. (2017). The functional role of planktonic mixotrophs in altering seston stoichiometry. Aquat. Microbial Ecol. 79, 235-245. doi: 10.3354/ame 01832

Mooshammer, M., Wanek, W., Hämmerle, I., Fuchslueger, L., Hofhansl, F., Knoltsch, A., et al. (2014). Adjustment of microbial nitrogen use efficiency to carbon: nitrogen imbalances regulates soil nitrogen cycling. Nat. Commun. 5:3694. doi: $10.1038 /$ ncomms4694

Mouquet, N., Moore, J. L., and Loreau, M. (2002). Plant species richness and community productivity: why the mechanism that promotes coexistence matters. Ecol. Lett. 5, 56-65. doi: 10.1046/j.1461-0248.2002. 00281.x

Nijs, I., and Impens, I. (2000). Underlying effects of resource use efficiency in diversity-productivity relationships. Oikos 91, 204-208. doi: $10.1034 / j .1600-0706.2000 .910120 . x$

Niu, S., Xing, X., Zhang, Z. H. E., Xia, J., Zhou, X., Song, B., et al. (2011). Water-use efficiency in response to climate change: from leaf to ecosystem in a temperate steppe. Glob. Chang. Biol. 17, 1073-1082. doi: $10.1111 / j .1365-2486.2010 .02280 . x$

Norberg, J., Swaney, D. P., Dushoff, J., Lin, J., Casagrandi, R., and Levin, S. A. (2001). Phenotypic diversity and ecosystem functioning in changing environments: a theoretical framework. Proc. Natl. Acad. Sci. U.S.A. 98, 11376-11381. doi: 10.1073/pnas.171315998 
Odum, H. T. (1957). Trophic structure and productivity of Silver Springs, Florida. Ecol. Monogr. 27, 55-112. doi: 10.2307/1948571

Paruelo, J. M., Lauenroth, W. K., Burke, I. C., and Sala, O. E. (1999). Grassland precipitation-use efficiency varies across a resource gradient. Ecosystems 2, 64-68. doi: 10.1007/s100219900058

Plum, C., Hüsener, M., and Hillebrand, H. (2015). Multiple vs. single phytoplankton species alter stoichiometry of trophic interaction with zooplankton. Ecology 96, 3075-3089. doi: 10.1890/15-0393.1

Policy, H. W., Johnson, H. B., Marinot, B. D., and Mayeux, H. S. (1993). Increase in C3 plant water-use efficiency and biomass over Glacial to present C02 concentrations. Nature 361:61. doi: 10.1038/361061a0

Ptacnik, R., Moorthi, S. D., and Hillebrand, H. (2010). "Hutchinson reversed, or why need there to be so many species," in Advances in Ecological Research, Vol. 43, ed G. Woodward (Burlington, NJ: Academic Press), 1-43.

Ptacnik, R., Solimini, A. G., Andersen, T., Tamminen, T., Brettum, P., Lepistö, L., et al. (2008). Diversity predicts stability and resource use efficiency in natural phytoplankton communities. Proc. Natl. Acad. Sci. U.S.A. 105, 5134-5138. doi: $10.1073 /$ pnas. 0708328105

Rothhaupt, K. O. (1996). Laboratorary experiments with a mixotrophic chrysophyte and obligately phagotrophic and photographic competitors. Ecology 77, 716-724. doi: 10.2307/2265496

Saito, M. A., Goepfert, T. J., and Ritt, J. T. (2008). Some thoughts on the concept of colimitation: three definitions and the importance of bioavailability. Limnol. Oceanogr. 53, 276-290. doi: 10.4319/lo.2008.53.1.0276

Schmidtke, A., Gaedke, U., and Weithoff, G. (2010). A mechanistic basis for underyielding in phytoplankton communities. Ecology 91, 212-221. doi: $10.1890 / 08-2370.1$

Schwartz, M. W., and Hoeksema, J. D. (1998). Specialization and resource trade: biological markets as a model of mutualisms. Ecology 79, 1029-1038. doi: 10. 1890/0012-9658(1998)079[1029:SARTBM]2.0.CO;2

Shurin, J. B., Gruner, D. S., and Hillebrand, H. (2006). All wet or dried up? Real differences between aquatic and terrestrial food webs. Proc. R. Soc. B Biol. Sci. 273, 1-9. doi: 10.1098/rspb.2005.3377

Soares, A. R. A., Bergström, A.-K., Sponseller, R. A., Moberg, J. M., Giesler, R., Kritzberg, E. S., et al. (2017). New insights on resource stoichiometry: assessing availability of carbon, nitrogen, and phosphorus to bacterioplankton. Biogeosciences 14, 1527-1539. doi: 10.5194/bg-14-1527 $-2017$

Sperfeld, E., Raubenheimer, D., and Wacker, A. (2016). Bridging factorial and gradient concepts of resource co-limitation: towards a general framework applied to consumers. Ecol. Lett. 19, 201-215. doi: 10.1111/ele. 12554

Sprengel, C. (1826). "Über Pflanzenhumus, Humussäure und humussaure Salze," in Kastners Archiv für die Gesamte Naturlehre (Nürnberg), 124-220.

Sterner, R. (1997). Modelling interactions of food quality and quantity in homeostatic consumers. Freshw. Biol. 38, 473-481. doi: 10.1046/j.1365-2427. 1997.00234.x

Sterner, R. W., and Elser, J. J. (2002). Ecological Stoichiometry: The Biology of Elements from Molecules to the Biosphere. Princeton, NJ: Princeton University Press.
Sterner, R. W., Elser, J. J., Fee, E. J., Guildford, S. J., and Chrzanowski, T. H. (1997). The light:nutrient ratio in lakes: the balance of energy and materials affects ecosystem structure and process. Am. Natural. 150, 663-684. doi: $10.1086 / 286088$

Tarvainen, L., Räntfors, M., and Wallin, G. (2015). Seasonal and withincanopy variation in shoot-scale resource-use efficiency trade-offs in a Norway spruce stand. Plant Cell Environ. 38, 2487-2496. doi: 10.1111/pce. 12565

Thomas, M. K., Aranguren-Gassis, M., Kremer, C. T., Gould, M. R., Anderson, K., Klausmeier, C. A., et al. (2017). Temperature-nutrient interactions exacerbate sensitivity to warming in phytoplankton. Glob. Chang. Biol. 23, 3269-3280. doi: $10.1111 / \mathrm{gcb} .13641$

Toseland, A., Daines, S. J., Clark, J. R., Kirkham, A., Strauss, J., Uhlig, C., et al. (2013). The impact of temperature on marine phytoplankton resource allocation and metabolism. Nat. Clim. Chang. 3, 979-984. doi: $10.1038 /$ nclimate1989

Urabe, J., and Sterner, R. W. (1996). Regulation of herbivore growth by the balance of light and nutrients. Proc. Natl. Acad. Sci. U.S.A. 93, 8465-8469. doi: 10.1073/pnas.93.16.8465

Urabe, J., and Watanabe, Y. (1992). Possibility of $\mathrm{N}$ or P limitation for planktonic cladocerans: an experimental test. Limnol. Oceanogr. 37, 244-251. doi: 10.4319/lo.1992.37.2.0244

Verbeek, L., Matthias, V.anhamel, Edwin, B.erg, Fabio, T. T., Hanashiro, A. T., Gianuca, Maren, S., et al. (2018). Compositional and functional consequences of environmental change in Belgian farmland ponds. Freshw. Biol. 63, 581-596. doi: 10.1111/fwb.13095

Vitousek, P. (1982). Nutrient cycling and nutrient use efficiency. Am. Nat. 119, 553-572. doi: 10.1086/283931

Vrede, T., Dobberfuhl, D. R., Kooijman, S., and Elser, J. J. (2004). Fundamental connections among organism C: N: P stoichiometry, macromolecular composition, and growth. Ecology 85, 1217-1229. doi: 10.1890/ 02-0249

Wakefield, A. E., Gotelli, N. J., Wittman, S. E., and Ellison, A. M. (2005). Prey addition alters nutrient stoichiometry of the carnivorous plant Sarracenia purpurea. Ecology 86, 1737-1743. doi: 10.1890/04-1673

Yvon-Durocher, G., Dossena, M., Trimmer, M., Woodward, G., and Allen, A. P. (2015). Temperature and the biogeography of algal stoichiometry. Glob. Ecol. Biogeogr. 24, 562-570. doi: 10.1111/geb.12280

Conflict of Interest Statement: The authors declare that the research was conducted in the absence of any commercial or financial relationships that could be construed as a potential conflict of interest.

Copyright $\odot 2019$ Hodapp, Hillebrand and Striebel. This is an open-access article distributed under the terms of the Creative Commons Attribution License (CC BY). The use, distribution or reproduction in other forums is permitted, provided the original author(s) and the copyright owner(s) are credited and that the original publication in this journal is cited, in accordance with accepted academic practice. No use, distribution or reproduction is permitted which does not comply with these terms. 